\title{
Integrating Self-Sensing in Self-Healing Concrete: Towards a Biomimetic Approach to Repair
}

\author{
Kevin Paine ${ }^{1}$, Bianca Reeksting ${ }^{2}$, Hussameldin Taha $^{1}$ and Susanne Gebhard ${ }^{2}$ \\ ${ }^{1}$ BRE Centre for Innovative Construction Materials, University of Bath, United Kingdom, \\ k.paine@bath.ac.uk; h.m.taha.abdalgadir@bath.ac.uk \\ ${ }^{2}$ Department of Biology and Biochemistry, University of Bath, United Kingdom, \\ b.j.reeksting@bath.ac.uk; s.gebhard@bath.ac.uk
}

\begin{abstract}
Material degradation of our civil infrastructure is inevitable, and regular maintenance is required to mitigate against failure during the service-life. However, understanding and knowledge of composites is now leading to the creation of concretes with autonomic self-healing capabilities. This development will transform our infrastructure by embedding self-immunity and resilience so that structures evolve over their lifespan enhancing durability and serviceability, improving safety and reducing maintenance costs. Research in the UK under the auspices of Resilient Materials for Life $(R M 4 L)$ has developed a suite of multiple-scale biomimetic self-healing concretes that can adapt and respond to damage without external intervention. This paper discusses the development of bacteria to precipitate calcite in cracks in concrete. Whilst bacteria-based healing is possible through several pathways, it is only now that a better understanding is permitting the optimization of the process. There are two key technologies for including bacteria healing in concrete: (i) encapsulation and (ii) vascular flow networks. Vascular flow networks permit continuous unlimited delivery of healing agents to internal areas of damage, facilitating repair on a reoccurring basis. However, in order to use them effectively human intervention is required to identify cracking and trigger healing processes. A more biomimetic approach is to provide the concrete with a form of self-sensing capability to enable it to initiate crack healing itself. Research using PZT sensors to detect cracking is described.
\end{abstract}

Keywords: Bacteria, Self-Healing, Self-Sensing, Flow Networks, PZT, Electromechanical Impedance.

\section{Introduction}

Concrete remains the principal construction material used in buildings and infrastructure worldwide. However, it is susceptible to degradation which, given current design guidance, is nearly always inevitable over its lifetime. This means that intervention and mitigation, in the form of maintenance and repair, is necessary to retain and recover high levels of performance and durability. However, in recent years a range of 'smart' concretes has been developed, including those with autogenous and autonomic self-healing and self-repairing capabilities. Consequently, it is now possible to embed self-immunity and resilience in our concrete buildings and structures such that they evolve over their lifespan. This has significant implications for enhancing durability and serviceability, improving safety and reducing maintenance costs.

Research to develop a biomimetic approach to the repair of concrete is being undertaken in the United Kingdom as part of the $£ 5 \mathrm{M}$ multi-disciplinary research project, Resilient Materials for Life (RM4L), a collaboration between Cardiff University, and the Universities of Bath, Bradford and Cambridge (Al-Tabbaa et al., 2018). RM4L has a broad remit to focus on tailoring 
self-healing cementitious systems for use in specific applications and to address different damage scenarios and conditions. Furthermore, important damage scenarios have been identified, including time-related and cyclic damage as well as chemical damage, including corrosion. In addition to self-healing attributes, RM4L is initiating novel research aimed at embedding self-sensing, self-diagnosing, self-immunisation and self-reporting capabilities into cementitious systems in order to develop truly biomimetic responses in our infrastructure materials and structures.

This paper reports on current research being undertaken within RM4L by the University of Bath in the areas of bacteria-based self-healing concrete (BBSHC) and self-sensing concrete. We also introduce the concept of a smart biomimetic self-healing concrete formed from the integration of three technologies: (i) bacteria-mediated calcium carbonate precipitation, (ii) vascular flow networks (VFN) and (iii) electromechanical impedance (EMI) that could deliver long-term maintenance and repair of concrete buildings and structures without the need for human intervention.

\section{Bacteria-Based Self-Healing}

In order to achieve autonomic healing in concrete, a wide range of healing agents have been studied over the last 20 years. These healing agents need to be compatible with the cementitious matrix and their speed of reaction has to be appropriate to eliminate ingress of harmful pollutants (chlorides, sulfates etc.). In general, healing agents with low viscosity and high

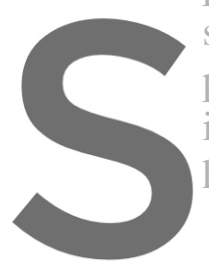
sorptivity have been pre properties, they are genet is a search for a suitab having some success wit However, an alternative is to use of bacteria within the crack. Calcium carbonate occurs nat its use as a healing compound is entirely appropriate

and providing them with the nutrients that they need to grow. Whilst the bacteria are in their spore form, they are inactive. However, when conditions become favourabie, they germinate into active cells and these multiply. These more favourable conditions occur when a crack forms in the concrete and water and oxygen ingress.

The presence of bacteria near a crack will aid the formation of calcium carbonate should the local environment be rich in dissolved inorganic carbon (DIC) and $\mathrm{Ca}^{2+}$ ions (Figure 1). For this reason, growth media containing both carbon and calcium sources are normally used simultaneously with the spores as healing agents. In general, bacteria-based self-healing of concrete can occur because of either ureolytic or non-ureolytic metabolism.

Research at Bath has performed a comparison between how ureolytic and non-ureolytic environmental bacteria precipitate calcium carbonate in order to understand how these mechanisms differ and how we can apply this knowledge to the improvement of self-healing concrete (Reeksting et al., 2020). In this study, environmental bacteria were surveyed for their ability to precipitate calcium carbonate and both the mechanism and resulting precipitates were examined. It was shown that while ureolytic bacteria cause the most rapid precipitation, nonureolytic bacteria were capable of producing similar amounts of calcium carbonate. In addition, 
the crystals resulting from non-ureolytic carbonate precipitation appeared to have more organic components and subsequently occupy larger volumes (Figure 2, left), this is likely beneficial for crack sealing application as for the same amount of calcium a larger precipitate can be formed. Indeed, non-ureolytic bacteria caused a more consistent crack healing and subsequent recovery of water tightness (Figure 2, right).

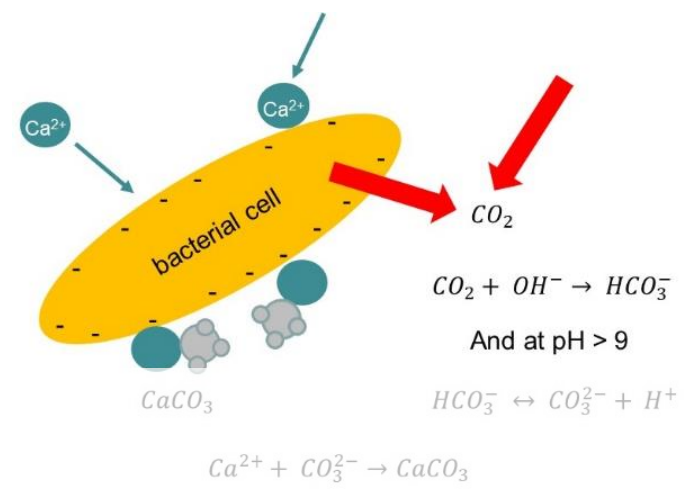

Figure 1. Process of calcium carbonate precipitation in a concrete crack (adapted from Dhami et al., 2013).

To date, self-healing of cementitious composites at Bath has focused on non-ureolytic bacteria, e.g., Bacillus pseudofirmus and Bacillus cohnii (Sharma et al., 2017). The spores of the bacteria have been encapsulated under vacuum in a light, The growth media, yeast extract and a calcium s been added either dire

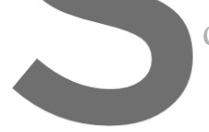
depending on the application.
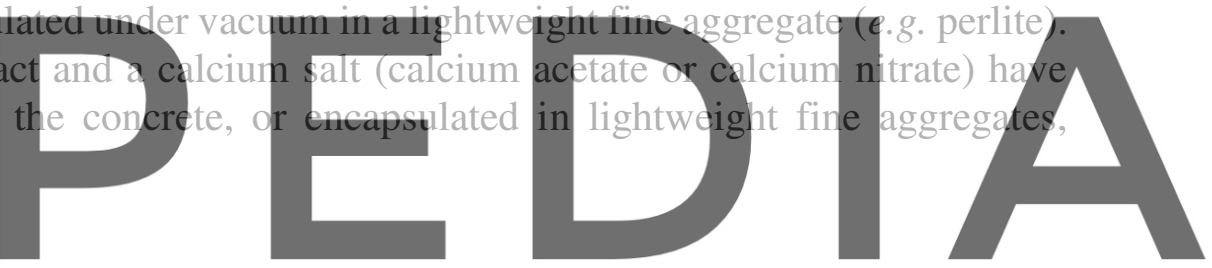

Register for free at https//www.scipedia.com to download the version without the watermark
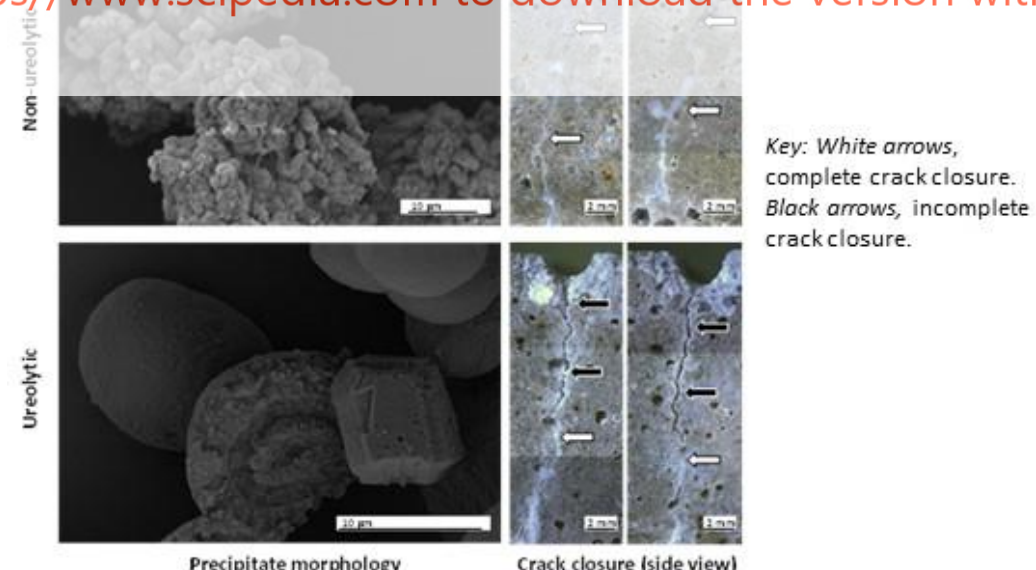

Black arrows, incomplet crack closure.

Figure 2. Crystal morphology and crack sealing in mortars containing either non-ureolytic or ureolytic bacteria. Left, electron micrographs of representative precipitate produced by non-ureolytic (top) and ureolytic (bottom) bacteria. Right, crack healing down the side of cement mortars at 8 weeks healing. 
It has been shown that the lightweight fine aggregates rupture on cracking releasing the healing agents in a form that enables calcium carbonate precipitation and healing to take place and that the concrete recovers its water tightness (Alazhari et al., 2018).

However, a concern with the use of lightweight aggregates is that they may not distribute homogeneously throughout the matrix. Consequently, there are some concerns (although not to date replicated in laboratory tests) that cracks may entirely miss the aggregates. For this reason, research at Bath has also considered supplying the spores and/or the growth media in microcapsules (Paine et al., 2019). We have shown that the encapsulation of spores by, for example, the complex coacervation technique, creates few technical issues and that high yields of spores can be obtained in small microcapsules $(180 \mu \mathrm{m})$. However, encapsulation of growth media is more difficult and only low loadings could be obtained and the microcapsules were much larger $(\sim 609 \mu \mathrm{m})$. In both cases, however, it was shown that the microcapsules rupture upon cracking of the concrete and that crack closure and recovery of water tightness occurs. That said, whilst the encapsulation of bacteria and growth media in concrete has proven successful there are some elements of this technique that could still be improved upon.

Firstly, the use of encapsulation means that the quantity of growth media in the concrete is fixed, limiting the amount of bacterial growth and the volumes of calcium carbonate precipitated. The addition of further growth media, such as yeast extract, directly into the concrete will substantially retard the cement hydration; whilst the calcium source is likely to carbonate and be unusable by the bacteria. The encapsulation of these growth media in

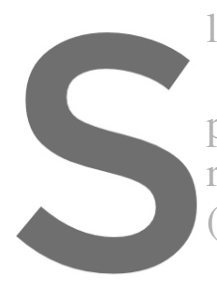
lightweight aggregates

\section{Furthermore, recent}

precipitation in concrete

researchers have attenp

(Zhang et al., 2016)

Consequently, it has
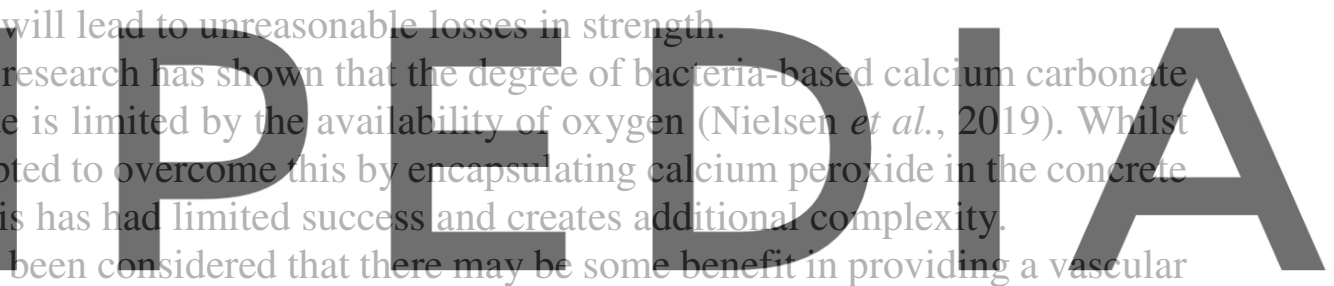

flow network (VFN) within the concrete that can supply oxygen and nutrients to the crack when

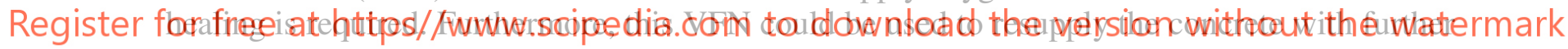
spores and nutrients to permit it to self-heal again should the crack reoccur at the same place.

\section{Vascular Flow Networks}

VFN systems have been considered as a viable technique for providing self-healing in materials as they more readily simulate the way flora and fauna heal themselves (White et al., 2001). A wide range of healing agents or supplies can be pumped through a VFN to the site of damage as and when required. The reservoir of healing agent can be readily topped up allowing for multiple healing events and the healing agent can be varied to suit the type of damage.

However, until recently the use of VFN for concrete had created problems; primarily because the glass used to create the channels tended to break during casting. For this reason, a novel approach has been developed at Cardiff University (Davies et al., 2015). Here, shrinkable polyurethane tubes are embedded in the concrete that can easily be removed after the concrete has hardened around them. This leaves a hollow network within the concrete. When healing is required, air can be removed from the VFN and the healing agents then added remotely and pumped through under pressure. 
The addition of a 2-dimensional VFN to a bacteria-based self-healing concrete wall was trialled as part of a large-scale demonstration of self-healing techniques carried out as a forerunner to the RM4L project (Paine et al., 2018). The wall consisted of both bacteria-based self-healing concrete and conventional concrete as shown in Figure 3. Bacteria-based selfhealing concrete was only added to the wall at the section where cracking was designed to occur (Figure 3b). A vascular flow network consisting of $4 \mathrm{~mm}$ diameter channels was placed in the zone most susceptible to cracking. The network was created using polypropylene tubes which were removed from the concrete once it had hardened. The network channels were joined using 3D printed joints made from polylactic acid. Whilst the VFN was included to permit later addition of further growth media, bacteria or oxygen as required it was never actually used in this way and bacterial healing was allowed to progress without interference
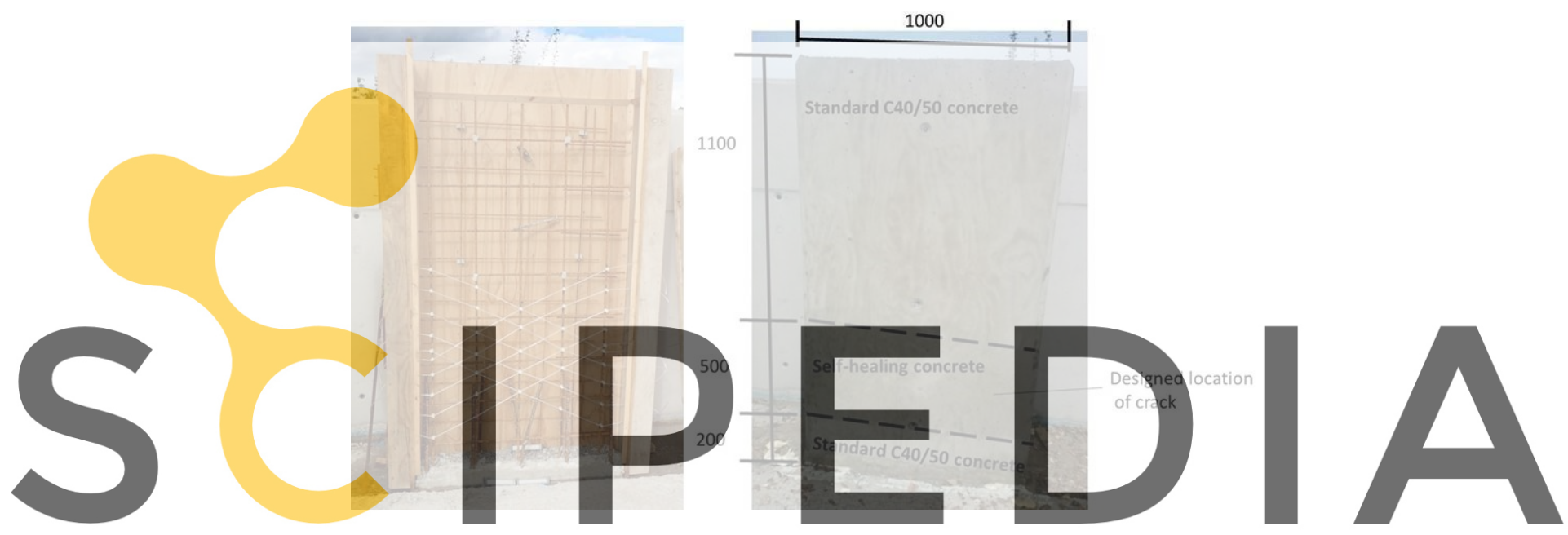

Figure 3. Large-scale demonstration of a bacteria-based self-healing concrete with: (a) VFN installed prior to

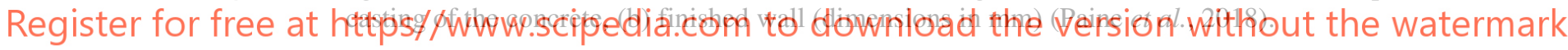

However, a principal problem with a VFN is that the release of the healing agents is not initiated by the cracking of the concrete. In general, it requires some form of monitoring system, often just visual observation, to detect the cracking and then human intervention is required to upload the healing agents and pressurize the system to pump the those healing agents through the network. However, recent research at Bath has been investigating the suitability of selfsensing systems that may detect and diagnose the formation of cracks, and their repair, within concrete. This sensing could potentially be used to trigger the healing system.

\section{Triggering Healing Systems}

Whilst there has been much research into the use of sensors for structural health monitoring, as far as we are aware there has been no research where autonomic self-healing responses have been triggered by sensors embedded within concrete. This is therefore a novel area of research.

Piezoelectric materials are popular sensors due to their ability to detect a wide range of parameters (stress, temperature, cracks and damage) and due to their high sensitivity, stability 
and low cost. There has been significant research with lead zirconate titanate (PZT) transducers. Of note is the use of electromechanical impedance (EMI) in which the PZT transducer works as both an actuator and detector simultaneously. Damage in a structure can be observed from fluctuations in the admittance/impedance signature which are caused by changes in the intrinsic material properties such as mass, stiffness and damping.

To better understand how a sensing system could be used to trigger healing once damage occurs and deactivate after repair, research has been carried out at Bath to understand how the EMI response of a PZT responds in both damage and repair scenarios (Taha et al., 2019).

This research has shown that localized damage in mortar beams, can be detected by a surface mounted PZT transducer located up to $220 \mathrm{~mm}$ away from where the damage has occurred. It was further observed that as the damage level increased, and approached the PZT, that the difference between the initial admittance signature and subsequent signatures increased, see Figure 4(a). This behavior was quantified by the root mean square (RMSD) response shown in Figure 4(b). On the other hand, when the damage was repaired, using a cement paste, it was observed that the RMSD gradually decreased (Figure 5). This indicated at least a partial recovery of properties due to the repair.
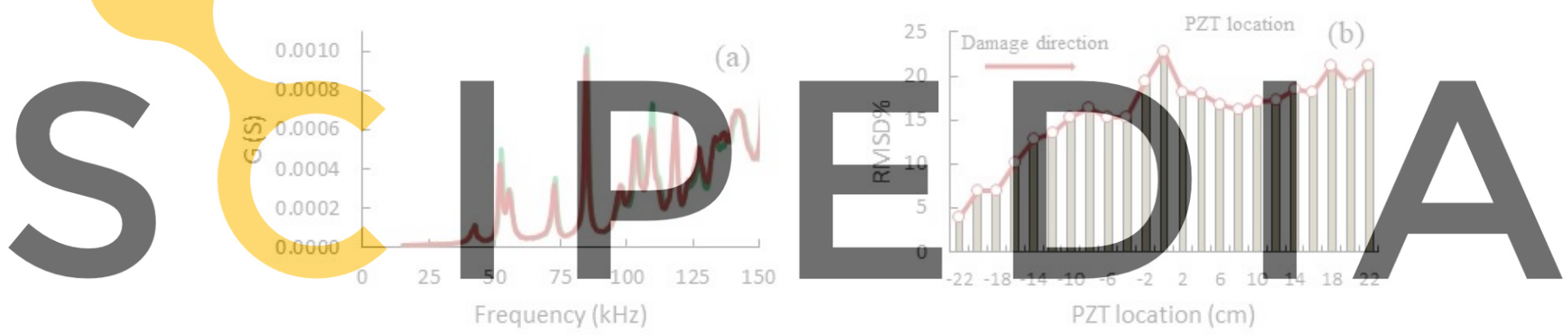

Register for free at https//www.scipedia.com to download the version without the watermark Figure 4. (a) Admittance signature for PZT before and after damage, (b) RMSD\% as the damage approaches and distances from the PZT sensor.

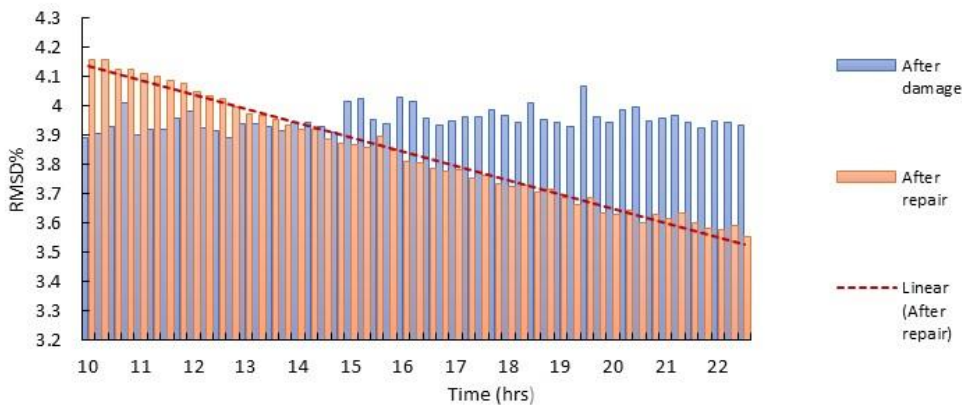

Figure 5. RMSD behavior 10 hours after repair as compared with the RMSD after damage. 


\section{Integration of Technologies}

As described above research is being undertaken at the University of Bath and partner universities within the RM4L programme grant to develop these three technologies. Whilst these developments are primarily taking place individually, there is a proposition that they could be integrated to form a smart biomimetic self-healing concrete, as shown schematically in Figure 6. Here a concrete building or structure can be cast using BBSHC around an embedded VFN, with PZT sensors, or some other form of sensing, strategically placed within or on the surface of the concrete. When a crack occurs the bacterial activity autonomically heals the cracks by precipitating calcium carbonate. However, simultaneously, a sensor detects that cracking has occurred. If it detects, after a given period, that the degree of healing is insufficient it triggers through an interface the activation of the VFN. Consequently, oxygen and/or further growth media are pumped through the VFN to the site of the crack from an external reservoir. Once the sensors have identified that healing is sufficient, they stop supplying oxygen and/or growth media. It is possible that at this point further spores and nutrients could be pumped to the site of the crack to permit further autonomous healing and for the cycle to recommence should a crack reappear at the same location at some further point in time.
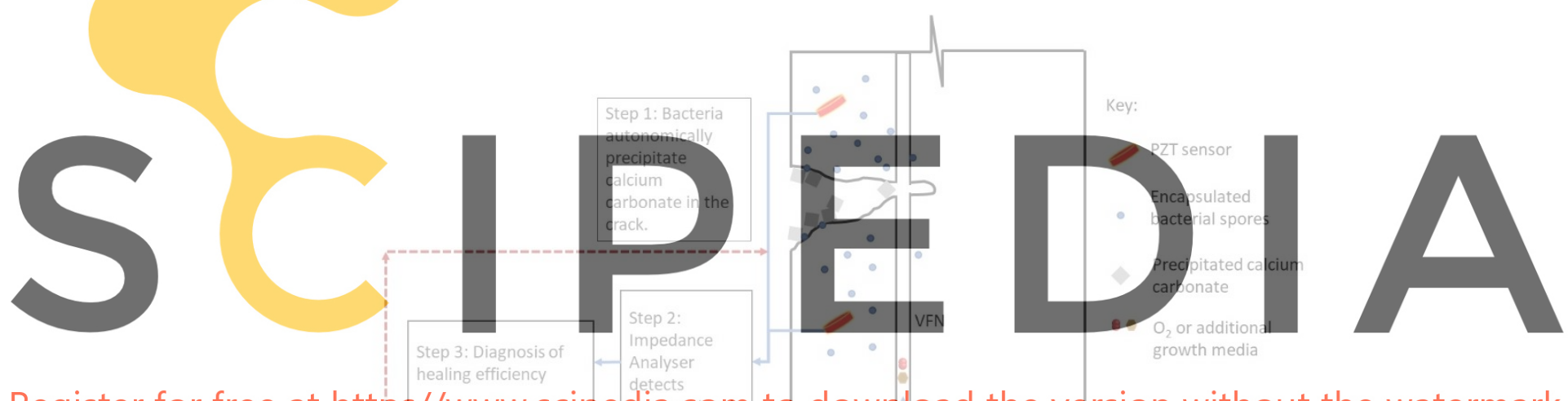

Register for free at https//WWW.scipedia.com
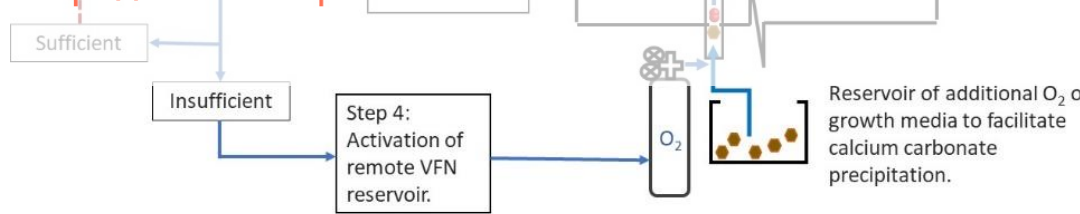

Figure 6. Schematic showing the integration of BBSHC, VFN and sensing technologies for biomimetic smart self-healing concrete.

\section{Conclusions}

- BBSHC, consisting of encapsulated spores and growth media, can be used to autonomically self-heal cracks in concrete as soon as they occur by precipitating calcium carbonate. However, the quantities of calcium carbonate precipitated may be limited by the availability of the growth media and oxygen.

- VFN can be formed in concrete and they permit remote healing agents and supplies to be pumped to the site of cracks to assist with bacteria-mediated calcium carbonate precipitation. 
- EMI has potential as a sensing technology to identify the degree of healing (quantity of calcium carbonate precipitated) in cracks. When interfaced with appropriate software it can be used to trigger the supply of healing agents through the VFN.

\section{Acknowledgements}

The authors wish to thank the EPSRC for their funding of the Resilient Materials for Life (RM4L) programme grant (EP/P02081X/1).

\section{ORCID}

Kevin Paine: http://orcid.org/0000-0001-7455-7002

Bianca Reeksting: https://orcid.org/0000-0003-1219-9574

Hussameldin Taha: https://orcid.org/0000-0002-6167-7598

Susanne Gebhard: http://orcid.org/0000-0003-4783-6115

\section{References}

Al-Tabbaa, A., Lark, B., Paine, K., Jefferson, T., Litina, C., Gardner, D. and Embley, T. (2018). Biomimetic cementitious construction materials for next-generation infrastructure. Proceedings of the Institution of Civil Engineers - Smart Infrastructure and Construction, 171(2), 67-76. doi: 10.1680/jsmic.18.00005

Alazhari, M., Sharma, T., Heath, A., Cooper, R. and Paine, K. (2018). Application of expanded perlite encapsulated bacteria and growth media for self-healing concrete. Construction and Building Materials, 160, 610-619. doi: 10.1016/j.conbuildmat.2017.11.086

Davies, R.E., Jefferson, A., Lark, R. and Gardner, D. (2015). A novel 2D vascular network in cementitious materials. fib Symposium, Copenhagen, Denmark

Dhami, N.K., Reddy, M. engineered application

Giannaros, P., Kanellopoulos sodium silicate. Smart Moterials a

Nielsen, S.D., Koren, K., Löbmann, $\mathrm{CaCO}_{3}$ precipitation in $\mathrm{s}$ 104, 365-375. doi: 10.1007/s00253-019-10215-4
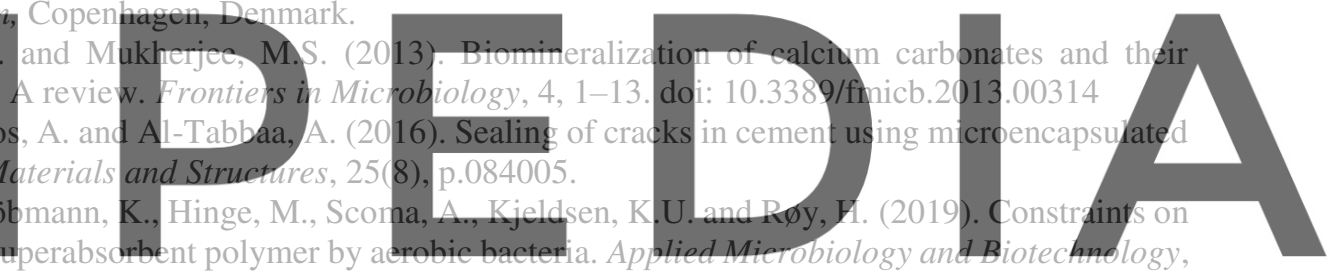

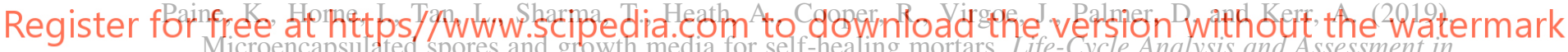
Civil Engineering: Towards an Integrated Vision. Taylor \& Francis Group.

Paine, K., Sharma, T., Alazhari, M., Heath, A. and Cooper, R. (2018). Application and performance of bacteriabased self-healing concrete. In: A. Bertron and H.M. Jonkers, eds. Microorganisms-Cementitious Materials Interactions. Toulouse, pp.387-394.

Reeksting, B.J., Hoffmann, T.D., Tan, L., Paine, K. and Gebhard, S. (2020). In-depth profiling of calcite precipitation by environmental bacteria reveals fundamental mechanistic differences with relevance to application. Applied and Environmental Microbiology. 86(7). doi: 10.1128/AEM.02739-19

Sharma, T.K., Alazhari, M., Heath, A., Paine, K. and Cooper, R.M. (2017). Alkaliphilic Bacillus species show potential application in concrete crack repair by virtue of rapid spore production and germination then extracellular calcite formation. Journal of Applied Microbiology, 122(5), 1233-1244. doi: 10.1111/jam.13421

Taha, H., Ball, R.J. and Paine, K. (2019). Sensing of Damage and Repair of Cement Mortar Using Electromechanical Impedance. Materials, 12(23), doi: 10.3390/ma12233925

White, S.R., Sottos, N.R., Geubelle, P.H., Moore, J.S., Kessler, M.R., Sriram, S.R., Brown, E.N. and Viswanathan, S. (2001). Autonomic healing of polymer composites. Nature, 409(6822), 794-797. doi: 10.1038/35057232

Zhang, J.L., Wang, C.G., Wang, Q.L., Feng, J.L., Pan, W., Zheng, X.C., Liu, B., Han, N.X., Xing, F. and Deng, $X$. (2016). A binary concrete crack self-healing system containing oxygen-releasing tablet and bacteria and its $\mathrm{Ca}^{2+}$-precipitation performance. Applied Microbiology and Biotechnology, 100(24), 10295-10306. 